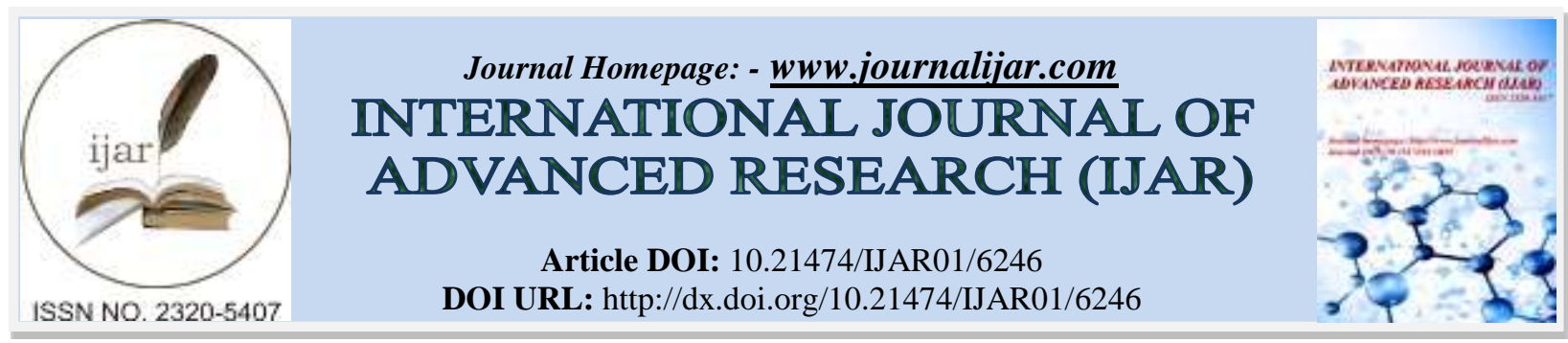

RESEARCH ARTICLE

\title{
A QUESTIONNAIRE STUDY ON APPLICATION OF A COMPREHENSIVE ORAL HYGIENE APP AMONG GENERAL POPULATION.
}

\section{Dr. Sneha Priya. K, Ms. Nadirah Izzatibinti Saidin, Ms. Chong Pin Sing, Ms. Koh Siew Mei, Mr. Soh Feng Jun, Ms. Goh Jin Hui, Mr. Deevatharshini a/p Jayabalan and Ms. Harpeven Kaur a/p Jasbir Singh. Assistant Professor, Faculty of Dentistry, Melaka Manipal Medical College, Madhavnagar, Manipal-576104.}

\section{Manuscript Info}

Manuscript History

Received: 07 November 2017

Final Accepted: 09 December 2017

Published: January 2018

\section{Abstract}

Copy Right, IJAR, 2018,. All rights reserved.

\section{Introduction:-}

The role of mobile applications has become central to our daily operations and activities. The dental office is no exception. The mobile applications have gained entry into everyday dental office and are playing an important role not only in administrative areas but also in the clinical aspects. For dental office administrators, the mobile apps are used for keeping appointments and track patients schedule and treatment log. The apps are being used extensively by the dentists for handy information on drugs and various surgical procedures. The apps are also being used by the patients for information on brushing techniques and as manuals for aftercare.

There are number of mobile apps already in the market ${ }^{1-3}$. The apps are designed to aid in the dental practice management, as clinical reference guides, for proper drug dosage, as reference tools, for information on recent updates on medical and dental health, to assist the dentist in coordinating with the lab for various indirect restorations, for viewing X-rays, virtual dentistry based apps to try different treatment procedures for a case, for information on Orthodontic, Periodontal and Oral surgical procedures.

The purpose of this study was to understand patient's awareness and obtain necessary information about an ideal patient friendly dental application by means of a descriptive Questionnaire. There are only few patient related apps ${ }^{1-}$

${ }^{3}$ that focus on comprehensive dentalcare. This Questionnaire was an attempt to gather information on what in the patient's view is an ideal Dental treatment App.

\section{Aims and Objectives:-}

- To collect the necessary information about a comprehensive oral hygiene mobile application from the general population.

\section{Objectives:-}

1. To conduct a detailed survey of the perception of general population on patient based oral hygiene application in mobile phones.

2. To evaluate the necessity of such application to manage dental treatment.

3. To evaluate the necessity of a comprehensive dental app versus other apps already available in the market. 


\section{Review Of Literature:-}

1. https://www.123dentist.com/top-10-dental-apps-for-smartphones/

a) Brush DJ-Brush DJ helps you to brush your teeth for the full two minutes to a randomly selected song from your playlist.

b) Dental Expert-Dental Expert is a patient's guide to understanding dentistry procedures, including some tips on how to care for your own smile.

c) Dental Phobia - Dental Phobia provides users with information that you need to deal with dental fears and phobias.

d) Braces Help - Braces Help is an informative app for patients wearing braces.

e) Teeth Whitener-Teeth Whitener is a fun app that allows you to see how you would look with a brighter smile

f) KidsDental-KidsDental uses animation to help you teach your child about their dental health in an entertaining and exciting way.

g) Dictionary of Dental Terminology - The Dictionary of Dental Terminology provides patients with a list of dental terms explained in a way that is simple and easy to understand.

h) My Smile - My Smile allows you to compare your tooth's colour shade on a 15 shade palate.

i) Monster Mouth DDS - Monster Mouth DDS is a fun app that allows you, a dentist for monsters, to journey to different situations where you have to solve monster's dental problems before their mouth slams shut

\section{2. http://dentistrybusiness.com/best-apps-for-dentists\#1467730946685-475777d5-95cd}

\section{a) dCStory: Patient Education}

Patient education tools play a critical role in sending difficult to understand clinical information to patients in an easy-to-understand style. This app provides several options of treatment plans and educational counseling with the help of high-definition 3D images.Patients can see more than 200 complex dental procedures, X-rays and photos. This app also gives you the opportunity to write out or sketch extra data on the image itself with the help of a stylus. This data can be printed or mailed online to the patient for viewing and reading at home.

b) Dental Demo Suite GP (DDS GP) is the most wide-ranging app for patient education. With this app, patients can see numerous dental problems and their treatments. Stock images are part of this app, but patient images can also be uploaded into an image library. With each image, particular points relating to a dental condition can be marked for discussion. This app is available on Blackberry, Android and iOS platforms.

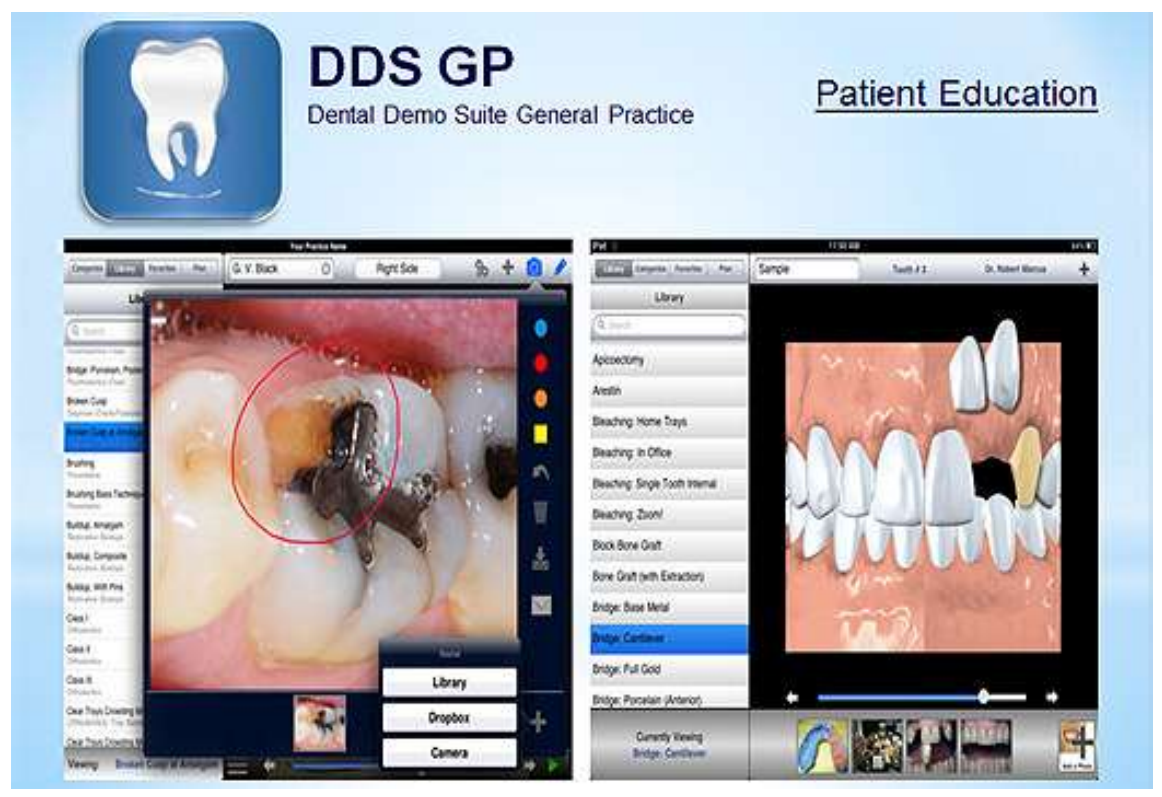

c) Mavro: Dental Spanish Guide

The Dental Spanish Guide app is perfect for dentists who don't speak Spanish but need to communicate with patients who only speak that language. The app allows dentists to choose phrases pertinent to dental treatments and 
relay those messages to their Spanish-speaking patient. Another feature of the app is a flash card feature that helps dentists practice important phrases between patients.

\section{d) Orasphere}

Would you like to explain a complex procedure to a patient in a way they can understand? Orasphere, an iPhone app, features an assortment of videos for patient education. The patient can view the procedure to better understand the treatment you are about to give, and you can reduce your liability by providing full pre-treatment information at the same time. While some dentists have complained that the app needs a greater variety of videos, most agree that the graphics of the existing videos are outstanding. The good news is there are more videos coming soon.

\section{e) Dental RX}

Also at your iTunes store, you can find a handy app called Dental RX. Use the app to send a complete prescription to your dental lab. The prescription can include all the different fields necessary for any lab work, including dentin color, midline and occlusal plane. You can also add photos to the RX for even more comprehensive instructions.
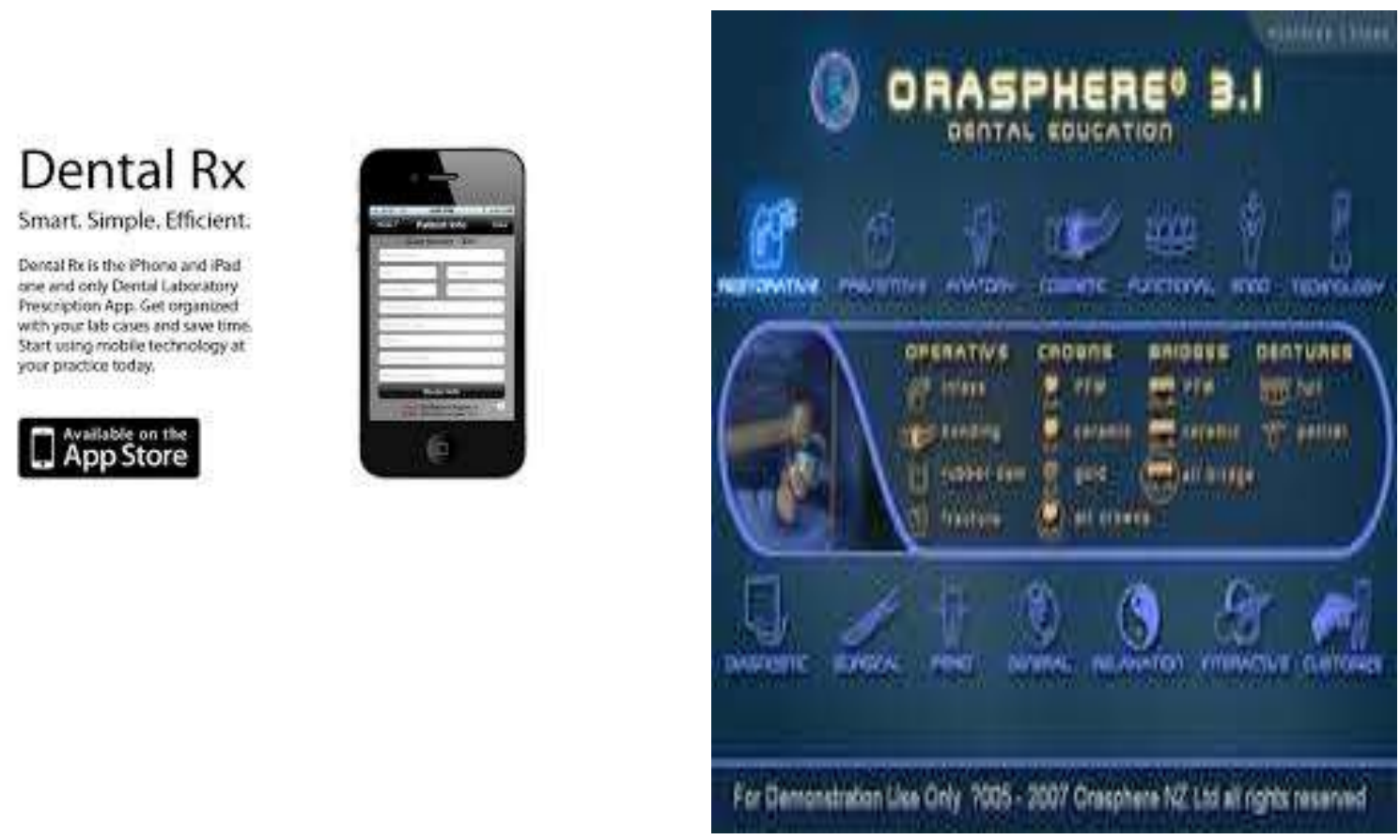

3. https://bibbynews.wordpress.com/2010/03/05/updated-list-of-iphone-apps-for-dentistry/

1) 1000 Dental Flashcards \& Quiz (\$1.99) Learn more than 1000 terms and concepts for the Dental Assisting National Board (DANB) certification test to become a Certified Dental Assistant (CDA) or Certified Orthodonitic Assistant (COA).

2) 3D Dental A-Z: (.99) detailed visual insights into Teeth, Anatomy, Instruments, Care, Implants \& more

3) 3D Dentist - the Chairside Assistant (free) help your patients understand the procedures you offer.

4) 3D Human Oral Cavity (6.99) images and illustrations of the Human Oral Cavity

5) Animated Tooth Quiz (\$1.99) Test your knowledge of human dental anatomy. For testing and educational purposes for people well-informed about the human teeth. Game consists of 48 illustrated questions with the animated images of each separate tooth.

6) AO Surgery Reference (free) includes sections on maxillofacial surgery, midface, mandible, dental alveolar, and skullbase/cranial vault

7) Brush DJ (free) Plays 2 minutes of music taken at random from your devices music library and has a visual display showing where to brush

8) Brush'em (free) helps you and your children to time brushing your teeth

9) Brush-n-Boogie (free) app to help you brush all the right areas of your mouth for the right amount of time.

10) Brush It Up (.99) Brush your teeth in a increasing difficulty game.

11) Brush with Jackson With supervision children use Jackson as a timer to brush for the recommended 2-3 minutes, twice a day and have fun whilst doing it. 
12) Cranial Nerves (\$4.99) Learn the 12 cranial nerves.

13) Crown \& Glory (free ) the dentist game

14) Darby Dental (free) distributor of dental supplies

15) DAT Dental Exam (.99) Practice exam to help dental professionals to prepare for the Dental Admission Test by the American Dental Association.

16) DAT Flashcards (free) Flashcards for the Dental Admissions Test

17) DcStory (free) educational and motivational tool for counseling dental patients.

18) DDS GP (\$399.99) for dentists, hygienists, and other dental professionals to increase case acceptance through better patient understanding of their dental health.

19) Den-Dic Dental dictionary. This app is free, but to obtain full access to the dictionary it requires a paid OnlineDental-Dictionary subscription which can be purchased via your iTunes account.

20) Endodontics (free) Endodontic journal.

21) Epocrates: Drug Reference

22) Evidence Based Dentistry: (free) systematic reviews, clinical recommendations and information for patients from the American Dental Association's Center for Evidence Based Dentistry (note, search for site in safari and then save as a bookmark to your home screen)

23) The Fake Dentist (free)

24) Flashcard Study System for the CDA exam (39.99) test questions on the Certified Dental Assistant Examination.

25) Flossy (.99) Flossy is an assistant that helps get you in the habit of flossing regularly.

26) Got Cavities (free) although the app is purely for entertainment it does provide a reminder to get a dental checkup regularly. With instructions on how to take a snap shot of your mouth and teeth this app magically evaluates tooth decay. Within less than a minute is returns the verdict and lets you know if you have cavities or whether your teeth are cavity free. Try it out on your friends and see who has the best dental hygiene. Show it to your Dentist and let them know how this little app keeps dental health at the top go your mind.

27) Happy Teeth (free) HAPPY TEETH is a FREE app that will allow you to enjoy fun music, and amazing graphics while at the same time showing you what quadrants of teeth you should be brushing. An adjustable timer will allow you to set the desired length of time to brush for.

28) HD Dentistry (.99) dental encyclopedia

29) HealthPoint Capital News - for the Orthopedic and Dental Industry (free): Get the latest news and analysis of the dental industry's markets, major players, technologies and trends.

30) Implant Treatment Guide Lite (free) explain complicated implant treatment options to your patients.

31) IMuco Gingival Recessions (\$64.99)Based on scientific studies and on his own clinical experience, the author, Dr. Olivier Carcuac shares with you his knowledge on mucogingival surgery for the treatment of gingival recessions.

32) Instant Teeth Whitener (1.99) see what you would look like with whiter teeth.

33) International Journal of Orthodontics (free) a quarterly peer-reviewed clinical journal published by the International Association for Orthodontics (IAO). The IJO features original scientific and clinical articles on orthodontics, plus an editorial, practice tips and office management hints.

34) IPanoramic (\$1.99) panoramic radiographs provide a general overview for the patient's teeth, bone, and jaws. A panoramic radiograph is usually used to detect and assess impacted 3rd molars, pathology, or in patients who are partially or fully edentulous.

35) iRomexis (free) dental imaging tool which displays images acquired by Planmeca dental equipment

36) iStudy Dental Anatomy (\$2.99)

37) Just Going to the Dentist (.99) for children, based on Mercer Mayer's Little Critter stories

38) Kid's Anatomy Human Teeth(.99) learn Human Teeth and its functioning.

39) Kids Brush: (1.99) major encouragement to brush everyday and keep the sugar bugs away.

40) KidsDental (4.99) uses animation to entertain your child while teaching them how to care for their teeth.

41) Kid's Dental Health (1.99) This educational interactive book helps parents teach their children in a fun and entertaining way all about the essentials of oral hygiene.

42) NBDE Part I Exam Prep (9.99): Practice game contains 400 questions to help you prepare for the test. $\$ 11.99$

43) NBDE Part II First Aid Q\&A: first 50 test questions are free. Set of $600 \$ 44.99$.

44) Netter's Advanced Head and Neck Flash Cards (39.99) Using the same anatomical illustrations from Netter's Atlas of Human Anatomy, these flash cards feature concise text to review muscles, bones, vessels, viscera and the joints.

45) Off We Go- Going to the Dentist (3.99) Fun book to prepare children to go to the dentist 
46) Oral Care Buddy (.99) tooth brush timer and patient education.

47) OralEye (free) Remote dental diagnosis platform.

48) Orashpere: (free) Dentist /patient education application describing the tooth anatomy and root canal procedures.

49) Orthodontic Products (free) provides the latest product news and technique tips, as well as articles by experts on topics including efficient treatment, staff management, and marketing methods.

50) StarTeeth (free) makes oral health fun for children

51) Straighten Me (free) educational app for orthodontics

52) Straumann Patient Education (free) This free app provides a convenient way to communicate the benefits of dental implants and describe treatment options and procedures, and allows dental professionals to customize the learning experience for each patient. It contains patient-friendly information, videos and animated graphics to help dental professionals inform their patients on dental implants solutions.

53) Straumann Restorative Flipchart (free) self-guiding tool the dental professional navigates through by indication type to determine the appropriate restorative component options that are available with the Straumann platform.

54) Suturing Techniques (\$3.99) Reviews suturing techniques in oral surgery

55) Tooth First Aid (.99): Quick help tool for dental emergencies.

56) tOOthFun (.99) Entertains children while they brush

57) Toothie (\$1.99) Guide to maintaining health teeth, gums and a beautiful smile

58) Tooth Morphology (4.99) for dental students

59) Tooth Morphology Exam preparation (1.99) useful study tool for dental undergraduate and postgraduate students in learning about and mastering the morphology of permanent dentition. It consists of clinical photographs with accompanying study notes and a chapter of short answer questions.

60) ToothNotes (.99) Tooth Notes records notes about your teeth. It helps you talk with your dentist by remembering the tooth or gum. In the $3 \mathrm{D}$ view, drag to rotate teeth.

61) ToothScout HD (free) assists the user in selecting the suitable teeth for beautiful and natural looking dentures which perfectly suit the patient's personal look.

62) Tray Timers (1.99) for anyone using clear aligners

63) Tx Simulator (free) Explains dental and orthodontic treatments

64) Tx Simulator II (free) uses 3D graphics to explain treatments to your patient.

65) ViewBox Dental (.99) turn your iPhone or iPad into an X-ray view box.

66) Virtual Dentist (\$19.99) professional dental simulation application that enables users to upload a photo and try out a variety of different dental procedures virtually on their own (or a patient's) photo.

67) Virtual Teeth Cleaning (.99) Take on the role of a Virtual Dentist - You are in control as you clean a patient's teeth. Scrape, Brush, Rinse and Floss your way to a healthy smile in this highly interactive educational game! Great for kids learning what to expect at a dentist visit, and adults who want to learn more about dental health.

68) XyloTeeth (.99) the ultimate musical instrument for dentists and their patients.

69) Yuck Mouth (free): game to help children brush properly

70) ZenDental (free): keep track of how long you brush your teeth, share your smile or ask us questions about your dental health.

\section{Materials and Methods:-}

\section{Materials and Methods}

A Total of 530 subjects, from the general population, above 18 years of age group were randomly selected for this study.

\section{Subject selection:-}

1. Both genders were included as subjects.

2. Population above 18 years of age were included in this study

\section{Exclusion criteria:-}

1. Population below 18 years of age

2. Population not using touch screen mobile phones.

\section{Methodology:-}

A descriptive continuous questionnaire was prepared using the guidelines. 
Questionnaire Survey:-

The survey consisted of 34 questions with objective type answering pattern.

\begin{tabular}{|c|c|c|c|c|}
\hline Sl.No & & & $\begin{array}{l}\text { Tick } \\
\text { If } \\
\text { YES }\end{array}$ & $\begin{array}{l}\text { Tick if } \\
\text { No( Give Reasons): }\end{array}$ \\
\hline 1. & \multicolumn{2}{|c|}{ Do You Use a Mobile Phone? } & & \\
\hline 2. & \multicolumn{2}{|c|}{$\begin{array}{l}\text { Do You Use Mobile Applications like Whats App and } \\
\text { Facebook? }\end{array}$} & & \\
\hline 3. & \multicolumn{2}{|c|}{$\begin{array}{l}\text { Do You Use Mobile Apps other than the mostly used apps } \\
\text { (Whats App and Facebook)? }\end{array}$} & & \\
\hline 4. & \multicolumn{2}{|c|}{$\begin{array}{l}\text { Do you think maintaining oral hygiene is important for our } \\
\text { health? }\end{array}$} & & \\
\hline 5. & \multicolumn{2}{|c|}{$\begin{array}{l}\text { Do you find the necessity of a Professional Self Help } \\
\text { App? }\end{array}$} & & \\
\hline 6. & \multicolumn{2}{|c|}{ Have you used any health based app before? } & & \\
\hline 7. & \multicolumn{2}{|c|}{$\begin{array}{l}\text { Do you find such health based apps useful in the present } \\
\text { times? }\end{array}$} & & \\
\hline 8. & \multicolumn{2}{|c|}{$\begin{array}{l}\text { Would You Use a Dental app before undertaking a Dental } \\
\text { Treatment? }\end{array}$} & & \\
\hline 9. & \multicolumn{2}{|c|}{ Are you aware of any treatment based mobile apps? } & & \\
\hline 10. & \multicolumn{2}{|c|}{ Have you used of a Professional Self Help App before? } & & \\
\hline 11. & \multicolumn{2}{|c|}{$\begin{array}{l}\text { What's your Current Age? } \\
0-18 \text { years old } \\
18-35 \text { years old } \\
35-65 \text { years old } \\
>65 \text { years old }\end{array}$} & & \\
\hline \multirow[t]{5}{*}{12.} & \multicolumn{4}{|c|}{ Do you want biological age to be included in the app? If yes, it should be classified as : } \\
\hline & \multicolumn{2}{|l|}{$\begin{array}{l}\text { - } \quad 0-18 \text { years old } \\
\text { - } \quad 18-35 \text { years old }\end{array}$} & \multirow{2}{*}{\multicolumn{2}{|c|}{$\begin{array}{l}\text { If No: } \\
\text { Give Reasons: }\end{array}$}} \\
\hline & 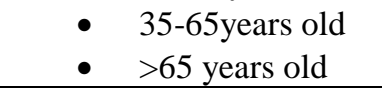 & & & \\
\hline & \multirow{2}{*}{$\begin{array}{ll}\text { - } & \text { Children } \\
\text { - } & \text { Youth } \\
\text { - } & \text { Adult } \\
\text { - } & \text { Geriatric Patient }\end{array}$} & $\begin{array}{l}\text { Tick if } \\
\text { YES }\end{array}$ & \multirow{2}{*}{\multicolumn{2}{|c|}{$\begin{array}{l}\text { If No: } \\
\text { Give Reasons: }\end{array}$}} \\
\hline & & & & \\
\hline 13 & \multicolumn{2}{|c|}{$\begin{array}{l}\text { Do you consider such an app helpful in dental treatment } \\
\text { management? }\end{array}$} & $\begin{array}{l}\text { Tick } \\
\text { If } \\
\text { YES }\end{array}$ & No( Give Reasons): \\
\hline 14 & \multicolumn{2}{|c|}{ Have you used free Mobile Apps? } & & \\
\hline 15 & \multicolumn{2}{|c|}{ Have You used paid Mobile Apps? } & & \\
\hline 16 & \multicolumn{2}{|c|}{$\begin{array}{l}\text { Would you want the app be customized to your dental } \\
\text { needs? }\end{array}$} & & \\
\hline 17 & \multicolumn{2}{|c|}{$\begin{array}{l}\text { Would you want the information of the treatment } \\
\text { procedures be divided branch wise : } \\
\text { For Ex: } \\
\text { 1. Endodontics-Root Canal Treatments, Fillings } \\
\text { 2. Prosthodontics-Replacement of Missing teeth } \\
\text { So On. }\end{array}$} & & \\
\hline 18 & \multicolumn{2}{|c|}{$\begin{array}{l}\text { Would providing information of different branches and the } \\
\text { relevant treatment procedures be helpful handy } \\
\text { information? }\end{array}$} & & \\
\hline 19 & \multicolumn{2}{|c|}{$\begin{array}{l}\text { Do you want the FAQs of the treatment procedure be } \\
\text { included before visiting the dentist? }\end{array}$} & & \\
\hline 20 & \multicolumn{2}{|c|}{ Would you like the app to have features demonstrating the } & & \\
\hline
\end{tabular}




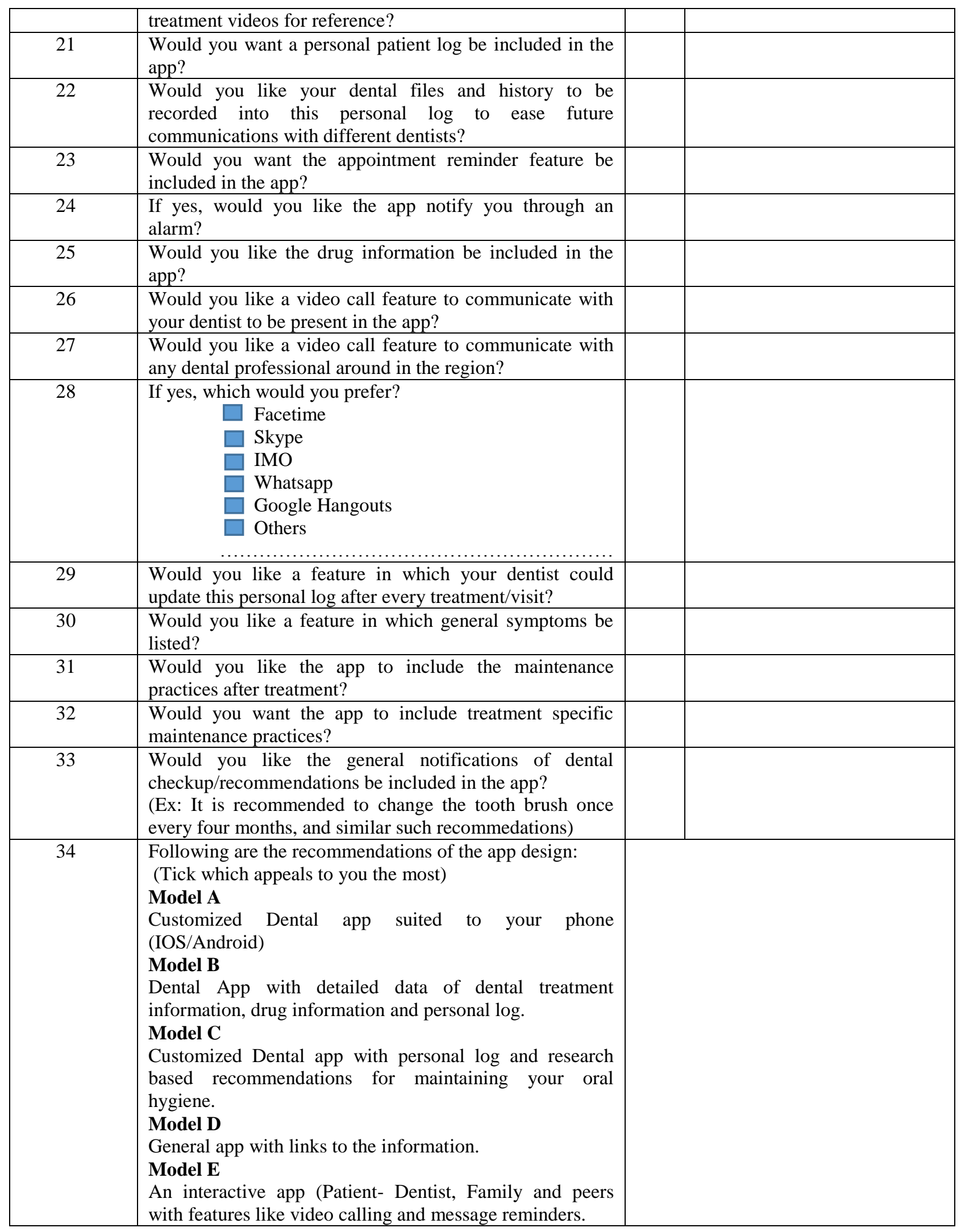




Any Other Features you want this app to include

\section{Table No.1}

The subjects included both the genders above 18 years irrespective of their educational background and ethnicity. The subjects recruited were general public.

The subjects recruited were family members, relatives, peers and friends. A prior informed consent was taken before undertaking the survey.

The data was subjected to statistical analysis.

\section{Table No. 2:-}

[Grab your reader's attention with a great quote from the document or use this space to emphasize a key point. To place this text box anywhere on the page, just drag it.]

\begin{tabular}{|c|c|c|c|}
\hline \multirow{3}{*}{\begin{tabular}{|l} 
\\
$\mathrm{Q} 18$
\end{tabular}} & & $\mathrm{~N}$ & $\%$ \\
\hline & No & 36 & $6.8 \%$ \\
\hline & Yes & 490 & $93.2 \%$ \\
\hline \multirow[t]{2}{*}{ Q19 } & No & 44 & $8.3 \%$ \\
\hline & Yes & 484 & $91.7 \%$ \\
\hline \multirow[t]{2}{*}{ Q20 } & No & 67 & $12.7 \%$ \\
\hline & Yes & 462 & $87.3 \%$ \\
\hline \multirow[t]{2}{*}{ Q21 } & No & 61 & $11.6 \%$ \\
\hline & Yes & 467 & $88.4 \%$ \\
\hline \multirow[t]{2}{*}{ Q22 } & No & 45 & $8.5 \%$ \\
\hline & Yes & 482 & $91.5 \%$ \\
\hline \multirow[t]{2}{*}{ Q23 } & No & 29 & $5.5 \%$ \\
\hline & Yes & 498 & $94.5 \%$ \\
\hline \multirow[t]{2}{*}{ Q24 } & No & 85 & $16.2 \%$ \\
\hline & Yes & 441 & $83.8 \%$ \\
\hline \multirow[t]{2}{*}{$\mathrm{Q} 25$} & No & 60 & $11.3 \%$ \\
\hline & Yes & 470 & $88.7 \%$ \\
\hline \multirow[t]{2}{*}{ Q26 } & No & 161 & $30.4 \%$ \\
\hline & Yes & 369 & $69.6 \%$ \\
\hline \multirow[t]{2}{*}{$\mathrm{Q} 27$} & No & 157 & $29.6 \%$ \\
\hline & Yes & 374 & $70.4 \%$ \\
\hline
\end{tabular}


Table No. 3:-

\begin{tabular}{|c|c|c|c|}
\hline \multirow{3}{*}{ Q29 } & & $\mathrm{N}$ & $\%$ \\
\hline & No & 35 & $6.7 \%$ \\
\hline & Yes & 491 & $93.3 \%$ \\
\hline \multirow{2}{*}{ Q30 } & No & 31 & $5.9 \%$ \\
\hline & Yes & 495 & $94.1 \%$ \\
\hline \multirow{2}{*}{ Q31 } & No & 19 & $3.6 \%$ \\
\hline & Yes & 507 & $96.4 \%$ \\
\hline \multirow{2}{*}{ Q32 } & No & 32 & $6.1 \%$ \\
\hline & Yes & 494 & $93.9 \%$ \\
\hline \multirow{2}{*}{ Q33 } & No & 51 & $9.7 \%$ \\
\hline & Yes & 474 & $90.3 \%$ \\
\hline \multirow[t]{21}{*}{ Q34 } & Missing & 16 & $3.0 \%$ \\
\hline & $\mathbf{A}$ & 124 & $23.3 \%$ \\
\hline & AB & 4 & $.8 \%$ \\
\hline & ABCE & 1 & $.2 \%$ \\
\hline & ABE & 2 & $.4 \%$ \\
\hline & $\mathrm{AC}$ & 2 & $.4 \%$ \\
\hline & AD & 1 & $.2 \%$ \\
\hline & ADE & 2 & $.4 \%$ \\
\hline & $\mathbf{A E}$ & 11 & $2.1 \%$ \\
\hline & ALL & 1 & $.2 \%$ \\
\hline & B & 152 & $28.6 \%$ \\
\hline & BC & 4 & $.8 \%$ \\
\hline & BCE & 1 & $.2 \%$ \\
\hline & BD & 2 & $.4 \%$ \\
\hline & $\mathbf{B E}$ & 4 & $.8 \%$ \\
\hline & $\mathrm{C}$ & 128 & $24.1 \%$ \\
\hline & CD & 1 & $.2 \%$ \\
\hline & $\mathbf{C E}$ & 5 & $.9 \%$ \\
\hline & D & 39 & $7.3 \%$ \\
\hline & DE & 2 & $.4 \%$ \\
\hline & $\mathbf{E}$ & 30 & $5.6 \%$ \\
\hline
\end{tabular}

\begin{tabular}{|l|l|l|}
\hline Q34 & N & $\%$ \\
\hline A & 124 & 24.03 \\
\hline B & 152 & 29.46 \\
\hline C & 128 & 24.81 \\
\hline D & 39 & 7.56 \\
\hline E & 30 & 5.81 \\
\hline Multiple preferences & 43 & 8.33 \\
\hline
\end{tabular}

\section{Results:-}

The results obtained show that the majority of the subjects chose Option B i.e. Dental app with detailed data of dental treatment information, drug information and personal log. Following this was preference for Option $\mathrm{C}$ i.e. customized dental app with personal log and research based recommendations for maintaining oral hygiene. Option A was also the preference for $24.03 \%$ of the subjects recruited which is based on customizing the dental app the suits the phone being used. There was no drastic difference in the preference percentages with $29.46 \%$ choosing Option B,24.81\% choosing Option C and $24.03 \%$ choosing Option A, respectively.

$8.33 \%$ chose multiple entries for Question no. 34 . 


\section{Discussion:-}

There has been an increase in the awareness levels of mobile apps used for dental clinical practice. There are various mobile applications available to the general public for specific treatment procedures in dental management. But there are only few mobile applications ${ }^{1-4}$ available that do everything that the patient needs for his dental treatment management. This questionnaire was hence chosen as a descriptive survey to know the awareness levels on various dental apps and also to obtain necessary information required to design a comprehensive patient based app for dental treatment management.

Age group of 18 years and above was chosen for convenience sake as the majority of mobile phone users fall in this age group. Both genders were chosen for this study to eliminate gender bias. Population that does not use touch screen mobile phones were excluded from this study. Population was chosen irrespective of their educational background to gain a wider understanding in this area from people who had diverse educational backgrounds.

The descriptive survey was designed based on the standard guidelines of continuous type survey design with 34 questions with objective type answers. The comment section included reasons for choosing "No" as the answer. Question No. 34 was designed with a futuristic app design in mind. The results obtained show that the majority of the subjects chose Option B i.e. Dental app with detailed data of dental treatment information, drug information and

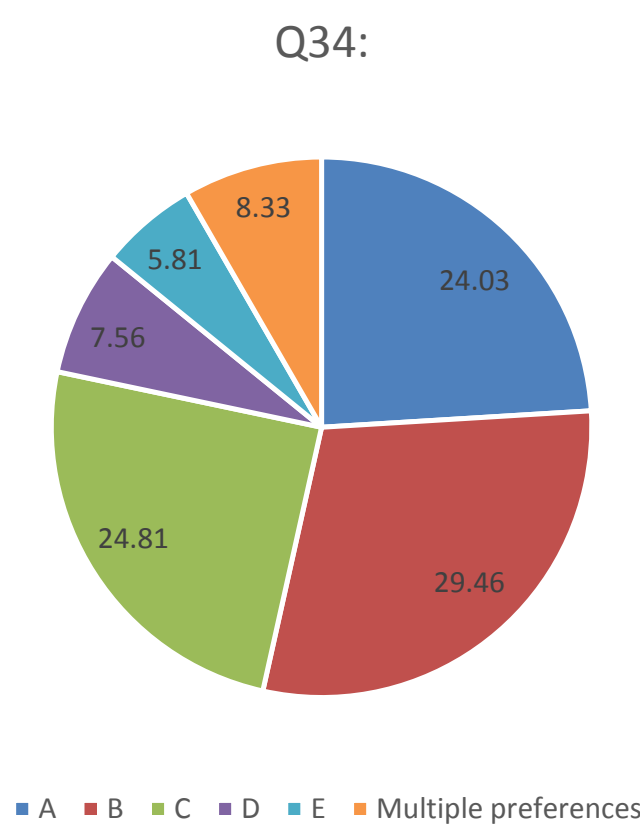

personal log. Following this was preference for Option C i.e. customized dental app with personal log and research based recommendations for maintaining oral hygiene. Option A was also the preference for $24.03 \%$ of the subjects recruited which is based on customizing the dental app the suits the phone being used. There was no drastic difference in the preference percentages with $29.46 \%$ choosing Option B,24.81\% choosing Option C and 24.03\% choosing Option A, respectively.

\subsection{3\% chose multiple entries for Question no. 34 .}

Hence there is growing need for an ideal patient based dental app for managing dental treatment. Since the preference for the ideal design model was same for Option A, B and C, it can be concluded that there is growing need for an ideal app though the ideal app design couldn't be ascertained.

The limitations of this study include smaller sample size. Other limitations are to perform this survey among different ethnicities to understand and confirm the ideal app design suited for all populations. 


\section{Limitations:-}

1. Additional research using the same methodology is needed, but with a larger sample size.

2. This study can be performed in demographic population with variable ethnicity, and educational background.

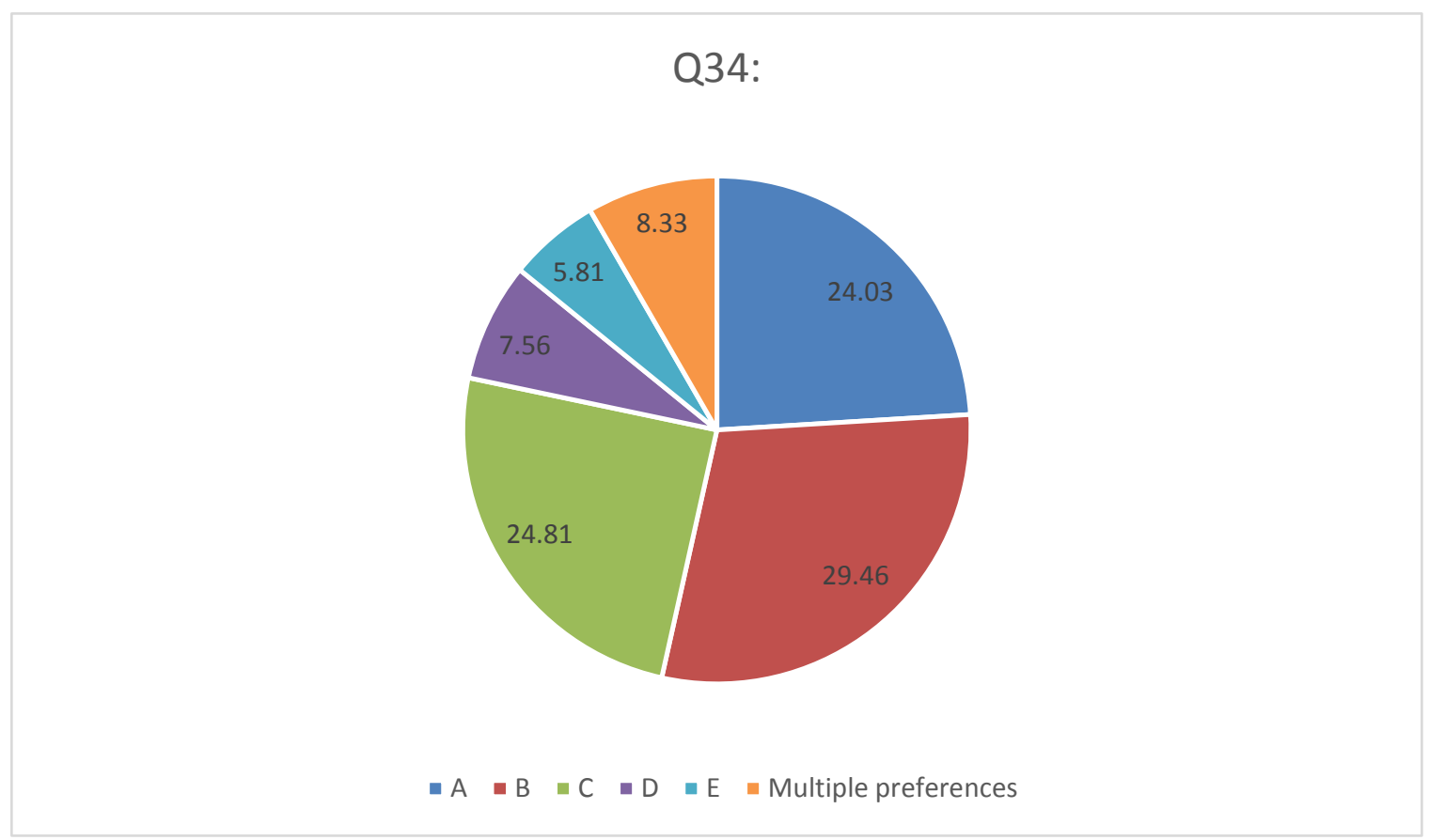

\section{Conclusion:-}

In the light of the results of this investigation the following conclusions can be derived:

1. There is increase in the awareness levels of mobile applications in the field of Dentistry.

2. There is increased need for a comprehensive oral hygiene app exclusively designed for patients.

3. Patients preferred a mobile app that provided a detailed data of dental treatment information, drug information and the one that has a personal log compared to an app design that's customized to patient's needs with patient $\log$ and recommendations for maintaining oral hygiene.

\section{Bibliography:-}

1. https://www.123dentist.com/top-10-dental-apps-for-smartphones/

2. https://www.123dentist.com/top-10-dental-apps-for-smartphones/

3. https://bibbynews.wordpress.com/2010/03/05/updated-list-of-iphone-apps-for-dentistry/ 